\title{
Knowledge of Farmers about Integrated Weed Management (IWM) Practices in Major Crops (overall) in Mahaboobnagar District of Telangana State, India
}

\author{
B. Rajashekar*, V. Sudharani, M. Madhavi and M. Jagan Mohan Reddy \\ Department of Agricultural Extension, Prof. Jayashankar Telangana State Agriculture \\ University, College of Agriculture, Rajendranagar, Hyderabad - 500030, Telangana, India \\ *Corresponding author
}

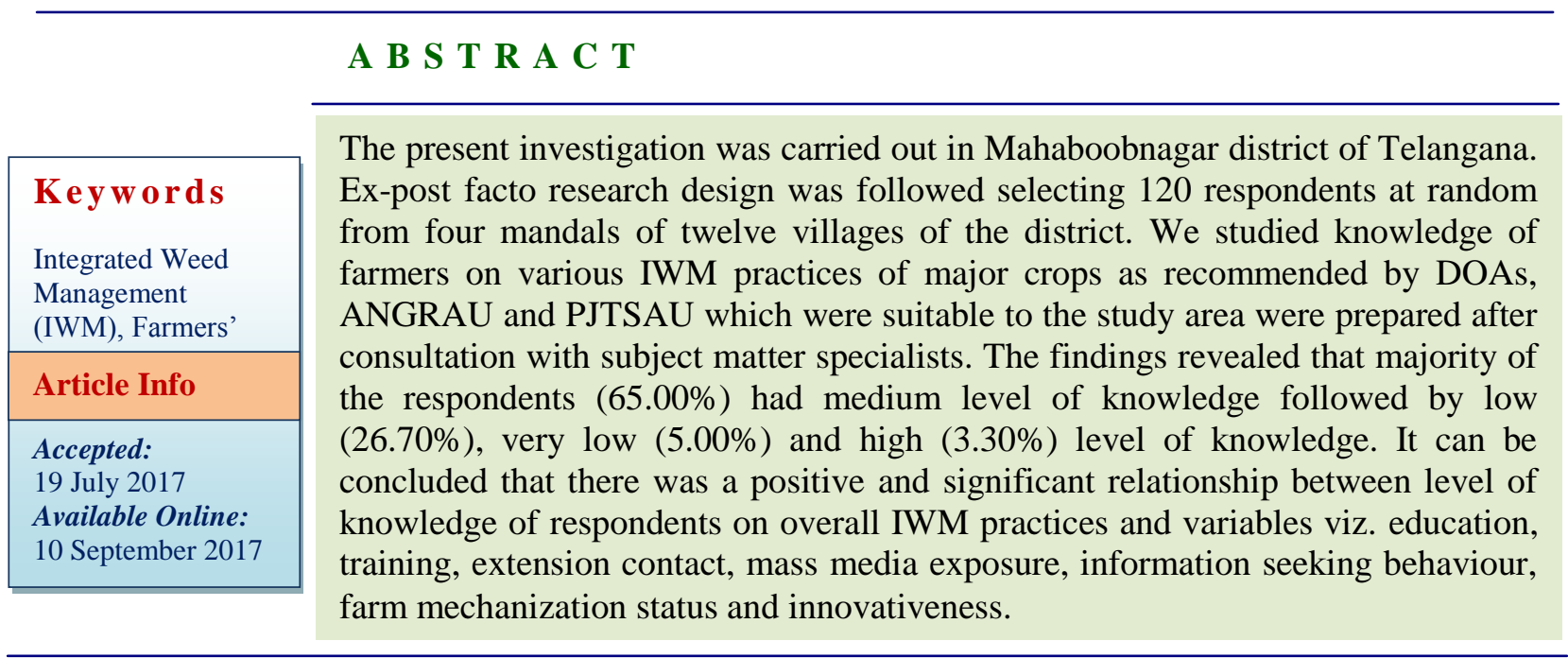

\section{Introduction}

Weeds are unwanted and undesirable plants which interfere with the utilization of land and water resources. Weeds are an important factor in the management of all land and water resources, but it effect is greatest on agriculture. The losses caused by weeds exceed the losses caused by any other category of agricultural pests. Of the total annual loss in agriculture produce, weeds account for 45 per cent, insect 30 per cent, disease 20 per cent and other pests 5 per cent. The different traditional methods like manual weeding, interculture operations and herbicide spraying farmers practicing is separately. Integrated weed management (IWM) is the control of weeds through a long-term management approach, using several weed management techniques such as: Physical control, Chemical control, Biological control and Cultural control methods. Therefore, a system approach to weed management known as "integrated weed management systems" (IWMS) is gaining importance.

\section{Materials and Methods}

Ex-post facto research design was used in the present investigation. The state of Telangana was chosen as the locale of the study and Mahaboobnagar district of Telangana was 
randomly chosen and 4 mandals in the district were selected randomly. From all the selected mandals, a list of villages containing farmers practicing IMW practices was obtained from Department of agriculture. From this list 3 villages from each mandal were selected randomly. Thus a total of 12 villages were selected for the study. Ten IWM practising respondents from each village were selected randomly using lottery method, thus making a total of 120 respondents for the study. For measuring respondent's knowledge on IWM practices, a knowledge test was developed. Data was collected using interview schedule developed for the study. Based on obtained scores the respondents were grouped into low, medium and high knowledge categories according to equal interval method. The collected data was analysed using appropriate statistical tools like Frequency and percentage, Class interval, Arithmetic mean $(\bar{X})$, Standard deviation and Co- efficient of correlation.

\section{Scoring and categorisation}

The overall knowledge test (Summing up all crops knowledge score) maximum and minimum possible scores was 0 to 90 . By summing up individual test scores the maximum and minimum obtained score was 14 to 51. Based on obtained scores the respondents were grouped into low, medium and high knowledge categories according to equal interval method as shown below.

\section{Results and Discussion}

From table 1 it was evident that, majority of the respondents $(65.00 \%)$ had medium level of knowledge followed by low $(26.70 \%)$, very low (5.00\%) and high (3.30\%) level of knowledge.

The results from table 3 indicated that majority of the respondents had medium level of knowledge followed by low, high and very low levels of knowledge respectively. The reason for this kind of result might be their medium education, extension contacts, risk orientation and innovativeness.

\section{Overall knowledge of farmers Vs profile characteristics}

The relationship between the overall level of knowledge of respondents with profile characteristics was tested by applying correlation technique and drawing relevant null and empirical hypothesis.

\section{Null hypothesis}

There will be no significant relationship between overall level of knowledge of respondents and their profile characteristics. Both of these are independent.

\section{Empirical hypothesis}

There will be significant relationship between level of knowledge of respondents and their profile characteristics. Both of these are dependent.

It is revealed from the table 2 that, calculated ' $r$ ' values between level of knowledge of respondents and education, extension contact, information seeking behaviour and innovativeness were greater than table ' $r$ ' values at 0.05 level of probability, whereas, the calculated ' $r$ ' value of the variables training, mass media exposure and farm mechanization status is greater than table ' $r$ ' value at 0.01 level of probability.

Therefore, it can be concluded that there was a positive and significant relationship between level of knowledge of respondents on overall IWM practices and variables viz. education, training, extension contact, mass media exposure, information seeking behaviour, 
farm mechanization status and innovativeness. Hence for these variables, null hypothesis was rejected and empirical hypothesis was accepted.

On the other hand the calculated ' $r$ ' values between knowledge and age, farm size, farming experience, risk orientation, input availability and labour availability less than table 'r' value.

Hence null hypothesis accepted and empirical hypothesis was rejected. Therefore, it can be concluded that there was no significant relationship between above characteristic and knowledge of famers.

The probable reason for this trend might be, now a days middle to young aged farmers with formal education, medium level of extension contacts, trainings undergone, mass media exposure, information seeking behaviour, access to farm mechanization and innovativeness are updating their knowledge regularly on production technologies including IWM practices.

\section{Relationship between profile characteristics with over all knowledge of respondents}

\section{Age Vs Knowledge}

The table 2 highlights that, the variable age was in positively non-significant relationship with knowledge of farmers, the reason might be that majority of the respondents were middle aged. This age farmers are less innovative as compared to young age.

The results were in confirmation with findings reported by Sajith (2004) and Munir et al., (2009).

\section{Education Vs knowledge}

The results inferred from table 2 revealed that there was a positive and significant relationship between education and overall level of knowledge of respondents. Education enhances the level of knowledge of respondents. Higher the education, wider and better will be the interaction. It is a wellknown fact that education brings desirable changes in knowledge, adoption and social status. The higher the education of a person, the more is his knowledge and vice versa. Hence this kind of relationship found in the investigation.

The results were in confirmation with findings reported by Hemanth (2002).

\section{Farm size Vs Knowledge}

The results inferred from table 2 revealed that there was a positive and non-significant association between farm size and overall level of knowledge of respondents. The higher the farm size, the more the area that is brought under cultivation of a crop which lead farmers to be careful and gain right knowledge. Probably this may be reason for this relationship.

Table.1 Distribution of the respondents based on their level of overall knowledge of IWM practices in selected crops

\begin{tabular}{|l|l|c|c|c|}
\hline S. No. & Level of knowledge & Class interval & Frequency & Percentage (\%) \\
\hline 1. & Very low & $11-14$ & 6 & 5.00 \\
\hline 2. & Low & $14-17$ & 32 & 26.70 \\
\hline 3. & Medium & $17-20$ & 78 & 65.00 \\
\hline 4. & High & $20-23$ & 4 & 3.30 \\
\hline
\end{tabular}


Table.2 Relationship between profile characteristics and level of knowledge of respondents on IWM practices

\begin{tabular}{|l|l|c|}
\hline S. No. & \multicolumn{1}{|c|}{ Characteristics } & Correlation coefficient (r) \\
\cline { 3 - 3 } & & Overall \\
\hline 1. & Age & $0.077 \mathrm{NS}$ \\
\hline 2. & Education & $0.188^{*}$ \\
\hline 3. & Farm size & $0.154 \mathrm{NS}$ \\
\hline 4. & Farming experience & $0.122 \mathrm{NS}$ \\
\hline 5. & Training in IWM & $0.446^{* *}$ \\
\hline 6. & Extension contact & $0.202^{*}$ \\
\hline 7. & Mass media exposure & $0.452^{* *}$ \\
\hline 8. & Information seeking behaviour & $0.252^{*}$ \\
\hline 9. & Farm mechanization status & $0.385^{* *}$ \\
\hline 10. & Risk orientation & $0.164 \mathrm{NS}$ \\
\hline 11 & Innovativeness & $0.195^{*}$ \\
\hline 12 & Input availability & $0.011 \mathrm{NS}$ \\
\hline 13 & Labour availability & $0.083 \mathrm{NS}$ \\
\hline
\end{tabular}

*Significant at 0.05 level of probability

**Significant at 0.01 level of probability

NS - Non significant

Table.3 Scoring and categorisation

\begin{tabular}{|c|l|c|}
\hline S. No. & \multicolumn{1}{|c|}{ Category } & Score \\
\hline 1. & Very low & $11-14$ \\
\hline 2. & Low & $14-17$ \\
\hline 3. & Medium & $17-20$ \\
\hline 4 & High & $20-23$ \\
\hline
\end{tabular}

\section{Faming experience Vs Knowledge}

The results inferred from table 3 revealed that there was a positive and non-significant relationship between farming experience and level of knowledge of respondents. Less the farming experience, less opportunity to gain/ acquire knowledge through experience.

The results were in confirmation with findings reported by Hemanth (2002).

\section{Training Vs Knowledge}

It is clear that there was a positive and significant relationship between training and overall level of knowledge of respondents, the reason might be that, training brings about desirable changes in knowledge, skill and attitude. Participation in training's improves farmers' interaction with scientists, officials and progressive farmers leading to their improved knowledge. This result is in conformity with that of Vasantha (2002) and Nirmala (2012).

\section{Extension contact Vs Knowledge}

The results revealed that there was a positive and significant relationship between extension contact and level of knowledge of respondents. Due to frequent extension 
contacts there will be definitely knowledge transfer from extension agent to fanner. Logically, a farmer with more extension contacts will have more knowledge on agricultural innovations. Hence this kind result was noticed.

This finding is in agreement with that of Nirmala (2012).

\section{Mass media exposure Vs Knowledge}

The results revealed that there was a positive and significant relation between level of knowledge and mass media exposure, the reason might be that respondents who have more mass media exposure will be up to date and may gain knowledge on IWM practices.

The results were in confirmation with findings reported by Gayathri et al., (2002) and Rajendra (2002).

\section{Information seeking behaviour Vs Knowledge}

The results indicate that there was a positive and significant relation between information seeking behaviour and level of knowledge of respondents. The reason might be that the respondents who had more information seeking behaviour had advanced knowledge regarding agricultural innovations. Naturally, the more the usage of information sources, the more the increase in knowledge for any individual on any aspect. Hence this kind of relationship might have appeared.

The results were in accordance with that of Jean et al., (2007).

\section{Farm mechanization status Vs Knowledge}

Perusal of the table 2 indicated that there was a positive and significant relationship between level of knowledge and farm mechanization status of the respondents. The reason might be that the farmers who follow modern ways crop production will try to use mechanized IWM practices. Farmers with adequate farm machinery available either with them or on rent would acquire required knowledge to use them effectively. Hence it can be clearly concluded that knowledge and farm mechanization status are positively correlated.

The results were in confirmation with findings reported by Malik et al., (2005).

\section{Risk orientation Vs Knowledge}

Perusal of the table 2 indicated that there was a positive and non-significant relationship between level of knowledge and risk orientation of the respondents. The reason might be that the farmer who is more risk taking will also be moderately innovative and keep acquiring knowledge by interacting with extension officers accessing information sources and becomes more knowledgeable than rest of the farmers.

\section{Innovativeness Vs Knowledge}

The variable innovativeness was found to have positively significant relationship with knowledge of farmers, the reason might be that even the moderately innovative respondents might have acquired required knowledge from various sources.

The results were in confirmation with findings reported by Nirmala (2012).

\section{Input availability Vs Knowledge}

The variable input availability was found to have positively non-significant association with knowledge of farmers, the reason might be that even if inputs are available, farmers may not know when to use, how much to use and other details. 


\section{Labour availability Vs Knowledge}

This variable labour availability was found to have positive and non-significant association with knowledge of farmers, the reason might be that if labour is available farmers can take up only weed management practice hence farmer acquire knowledge about IWM practices in crop production.

\section{References}

Gayathri, M.N., Narayana, G. K and Ranganna, B. 2002. Knowledge and adoption of improved post-harvest practices by farm women in redgram. Mysore Journal of Agricultural Sciences. 36: 77-86

Hemanthkumar, B., 2002. A study on attitude, knowledge and adoption of recommended practices by oriental tobacco farmers in Chittoor district of Andhra Pradesh. M.Sc. (Ag.) Thesis submitted to Acharya N G Ranga Agricultural University, Hyderabad.

Jean, C.C., Joep, S., Dang, D. Q., François, G., Nguyen, Van, L and Pham, T.H.T. 2007. Connecting marginal rice farmers to agricultural knowledge and information systems in Vietnam uplands. The Journal of Agricultural Education and Extension. 12(2): 109125.

Malik, R.S., Sherawat, R.S., Sube, S and Loveraj, S. 2005. Relationship of farmers' trait with knowledge of rapeseed-mustard production technology. J. of Oilseeds Res. 22 (1): 159-161.

Munir, H. N., Srivastava, S. R., Gadara, A. K and Yadav, V. P. S. 2009. Knowledge level about organic farming in Haryana. Indian Research Journal of Extension Education. 9(1).

Nirmala, 2012. A study on diffusion status and adoption of System of Rice Intensification (SRI) in Mahaboobnagar in Andhra Pradesh. M.Sc. (Ag.). Thesis. Acharya N.G. Ranga Agricultural University, Hyderabad.

Rajendra, K., 2002. A study on knowledge and adoption of recommended practices of hybrid jowar seed production in Kurnool district of Andhra Pradesh. M.Sc (Ag) Thesis, Acharya N.G Ranga Agricultural University, Hyderabad.

Sajith, G.K., 2004. Adoption of recommended package of practices by the coconut farmers of Mahe region of Union Territory of Pondicherry. M.Sc. (Ag) Thesis submitted to Acharya N G Ranga Agricultural University, Hyderabad.

Vasantha, R., 2002. Critical analysis of Integrated Pest Management practices (IPM) in relation to innovation-decision process among cotton growing farmers of Guntur district of Andhra Pradesh. Ph.D Thesis submitted to Acharya N. G. Ranga Agricultural University, Hyderabad.

\section{How to cite this article:}

Rajashekar, B., V. Sudharani, M. Madhavi and Jagan Mohan Reddy, M. 2017. Knowledge of Farmers about Integrated Weed Management (IWM) Practices in Major Crops (overall) in Mahaboobnagar District of Telangana State, India. Int.J.Curr.Microbiol.App.Sci. 6(9): 16161621. doi: https://doi.org/10.20546/ijcmas.2017.609.199 